\title{
Off-pump coronary artery bypass grafting attenuates morbidity and mortality for patients with low and high body mass index
}

\author{
W. Brent Keeling, MD, ${ }^{\mathrm{a}}$ Patrick D. Kilgo, MS, ${ }^{\mathrm{c}}$ John D. Puskas, MD, ${ }^{\mathrm{b}}$ Michael E. Halkos, MD, \\ Omar M. Lattouf, MD, ${ }^{\mathrm{b}}$ Robert A. Guyton, MD, ${ }^{\mathrm{b}}$ and Vinod H. Thourani, $\mathrm{MD}^{\mathrm{b}}$
}

\begin{abstract}
Background: Patients at high and low body mass index have been shown to experience higher morbidity and mortality when undergoing coronary artery bypass grafting. The purpose of this research was to compare outcomes of patients at body mass index extremes who underwent coronary artery bypass grafting with or without cardiopulmonary bypass.
\end{abstract}

\begin{abstract}
Methods: A retrospective review of 6801 patients with a body mass index $<25$ or $>35$ undergoing isolated, primary coronary artery bypass grafting from 1996 to 2009 at Emory Healthcare Hospitals was performed. Patients were compared by therapy either on-pump coronary artery bypass grafting $(n=3210)$ or off-pump coronary artery bypass grafting $(\mathrm{n}=3591)$. Salvage patients or those with concomitant operations were excluded. Comparisons were made using multivariable regression analysis, using a propensity score covariate calculated from 41 preoperative risk factors.

Results: A total of 6801 patients, including 4312 with a body mass index $<25$ (off-pump coronary artery bypass grafting, $\mathrm{n}=2083$; on-pump coronary artery bypass grafting, $\mathrm{n}=2229$ ) and 2489 with a body mass index $>35$ (off-pump coronary artery bypass grafting, $\mathrm{n}=1127$; on-pump coronary artery bypass grafting, $\mathrm{n}=1362$ ) were included for analysis. Society of Thoracic Surgeons predicted risk of mortality was significantly higher for both body mass index strata in patients undergoing off-pump coronary artery bypass grafting $(2.8 \% \mathrm{vs} 3.1 \%$ for body mass index $<25[P=.043]$ and $1.7 \%$ vs $1.8 \%$ for body mass index $>35[P=.049])$. For patients with a body mass index $<25$, multivariable analysis of outcomes showed a significant decrease in in-hospital mortality (adjusted odds ratio, 0.48; 95\% confidence interval, 0.28-0.82), stroke (adjusted odds ratio, $0.31 ; 95 \%$ confidence interval, 0.18-0.56), new-onset renal failure (adjusted odds ratio, $0.59 ; 95 \%$ confidence interval, 0.36-0.96), and prolonged ventilation (adjusted odds ratio, 0.50; 95\% confidence interval, 0.38-0.64). Longterm survival was unaffected by method of revascularization for either body mass index strata $(P>.05)$.
\end{abstract}

Conclusions: Patients with high and low body mass indices experience reduced morbidity and in-hospital mortality when undergoing off-pump coronary artery bypass grafting. Despite a higher risk profile, patients with a body mass index $<25$ who underwent off-pump coronary artery bypass grafting experienced a significant reduction in in-hospital mortality. (J Thorac Cardiovasc Surg 2013;146:1442-8)

Surgical coronary revascularization has been established as an effective method of providing a lasting source of nutrient blood flow to areas of ischemic myocardium. ${ }^{1-5}$ Long-term results of coronary artery bypass grafting $(\mathrm{CABG})$ reflect growing expertise with a variety of techniques and conduit choices. ${ }^{2,4-7}$ Excellent survival among a variety of subgroups undergoing CABG has been documented,

From the Division of Cardiothoracic Surgery, ${ }^{a}$ University of Louisville, Ky; the Clinical Research Unit, ${ }^{b}$ Division of Cardiothoracic Surgery, Joseph B. Whitehead Department of Surgery, and the Department of Biostatistics, ${ }^{c}$ Rollins School of Public Health, Emory University School of Medicine, Atlanta, Ga.

The funding for this study was provided by internal funds from the Division of Cardiothoracic Surgery Clinical Research Unit, Emory University, Atlanta, Ga.

Disclosures: Authors have nothing to disclose with regard to commercial support.

Received for publication Dec 19, 2011; revisions received May 15, 2012; accepted for publication Sept 13, 2012; available ahead of print Oct 18, 2012.

Address for reprints: Vinod H. Thourani, MD, Emory University Hospital Midtown, Cardiac Surgery, 550 Peachtree St, 6th Floor Medical Office Tower, Atlanta, GA 30308 (E-mail: vthoura@emory.edu).

0022-5223/ $\$ 36.00$

Copyright $(2) 2013$ by The American Association for Thoracic Surgery

http://dx.doi.org/10.1016/j.jtcvs.2012.09.035 including those with certain anatomic considerations like left main coronary artery stenosis and 3-vessel disease. ${ }^{8-10}$

Off-pump coronary artery bypass grafting (OPCAB) is a technique that aims to provide equivalent coronary revascularization without the assistance of cardiopulmonary bypass (CPB). Published results of patients undergoing OPCAB, however, have been mixed. In a large, randomized trial published recently that included $>2200$ patients, 1 -year composite outcomes and graft patency rates were worse in patients undergoing OPCAB when compared with onpump CABG (ONCAB). ${ }^{11}$ Other trials with more practiced surgeons, however, have found equivalent rates of mid-term graft patency and reductions in short- and mid-term mortality. ${ }^{12-14}$ Specifically, recent data indicated that patients at highest risk for mortality from $\mathrm{CABG}$ derive the greatest benefit from OPCAB. ${ }^{15}$

Low body mass index (BMI) has been investigated previously as an independent risk factor for morbidity and mortality following CABG. In a mixed cardiac surgical population of $>5000$ patients, Engelman and colleagues ${ }^{16}$ 


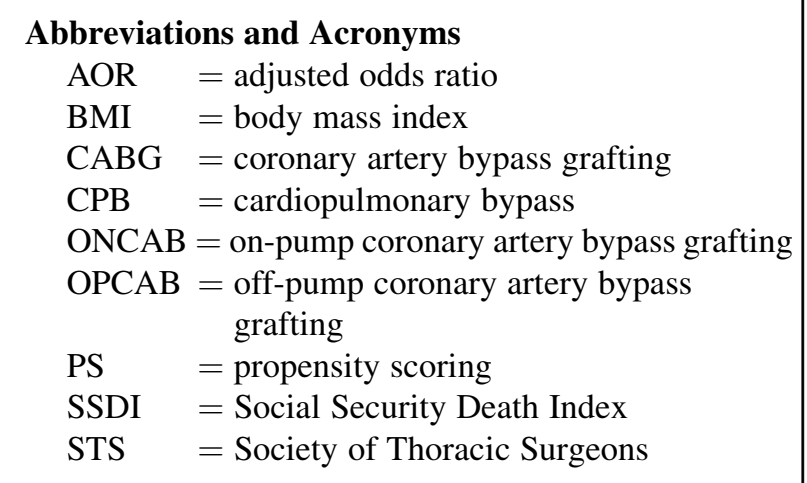

reported that low BMI as well as low preoperative serum albumin led to increased morbidity and mortality after cardiac surgery. More than $30 \%$ of these patients, however, underwent some type of valve surgery, and all procedures were performed with the aid of CPB. Potapov and associates ${ }^{17}$ reported that patients with a BMI $<25$ in 23,000 European patients experienced a significant increase in morbidity, including reintubation and reexploration for hemorrhage. More than 17,000 isolated CABG procedures were included for analysis, but OPCAB cases were not documented.

Because patients at body mass extremes have been proved to incur increased morbidity and mortality after $\mathrm{CABG}$, we sought to determine the impact of OPCAB on outcomes in these high-risk groups. The purpose of this research was to compare short- and long-term outcomes of ONCAB vs OPCAB for patients with a BMI $<25$ or $>35$.

\section{METHODS}

\section{Experimental Design}

This research sought to compare 2 different methods of coronary revascularization (ONCAB and OPCAB) and the outcomes of patients after the procedures. Patients were identified by querying the Emory University institutional Society of Thoracic Surgeons (STS) Adult Cardiac Database for consecutive patients who underwent isolated CABG at Emory Healthcare Hospitals between January 1, 1996, and December 31, 2009. Patients undergoing another concomitant cardiac procedure and salvage operations were excluded. Redo CABG patients, however, were included in this analysis.

During the study period, 19,935 patients underwent CABG and 6801 $(34.1 \%)$ met inclusion criteria and were included for analysis. A variable for conversion from $\mathrm{OPCAB}$ to $\mathrm{ONCAB}$ was collected starting only in 2002 and was unavailable for much of the study period; thus, patients were classified according to the treatment they ultimately received. Body mass index was calculated by dividing the patient's weight in kilograms by the square of the patient's height in meters. Each patient was classified as either $<25 \mathrm{BMI}$ or $>35 \mathrm{BMI}$. Patients in the range from 25 to $35 \mathrm{BMI}$ were excluded from the study. Extracted patient records included demographic data, preexisting comorbidities, and clinical outcomes. The study was approved by the Emory University institutional review board in compliance with Health Insurance Portability and Accountability Act regulations and the Declaration of Helsinki. The institutional review board waived individual patient consent secondary to the retrospective nature of the study.

\section{Procedural Information}

During the study period, 20 surgeons performed the procedures included in this analysis. Decisions regarding operative therapy (ONCAB vs $\mathrm{OPCAB}$ ) were made exclusively by the attending surgeon. For patients undergoing $\mathrm{ONCAB}$ procedures, standard $\mathrm{CPB}$ procedures were followed. Cold antegrade and/or retrograde cardioplegia was used routinely at the discretion of the attending surgeon. Typically, conventional CPB performed using roller head pumps, membrane oxygenators, cardiotomy suction, arterial filters, and moderate systemic hypothermia $\left(34^{\circ} \mathrm{C}\right)$. Off-pump CABG procedures were performed under normothermic conditions with the heart beating continuously. Cardiac positioning was facilitated by the use of commercially available stabilizers and positioning devices. For patients undergoing both $\mathrm{ONCAB}$ and $\mathrm{OPCAB}$ procedures, routine utilization of epi-aortic ultrasound scanning of the ascending aorta was used to assess for atheromatous disease prior to cannulation and/or the construction of proximal anastomoses. In general, proximal anastomoses for patients undergoing $\mathrm{ONCAB}$ were performed under a single crossclamp, and proximal anastomoses for patients who underwent OPCAB were performed with the aid of a partial occlusion clamp, although these methods varied by surgeon and patient.

\section{Outcomes and Long-Term Follow-up}

Postoperative clinical outcomes of interest included in-hospital mortality, permanent stroke, myocardial infarction, major adverse cardiac events (composite of death, permanent stroke or myocardial infarction), mediastinitis (deep sternal wound infection within 30 days), septicemia, worsening renal failure, new dialysis, and prolonged ventilation. Also, the Social Security Death Index (SSDI) is a publicly available national database of death records extracted from the U.S. Social Security Administration's Death Master File Extract. Patients with a Social Security number who have died since 1963 and whose death has been reported to the Social Security Administration are listed in the SSDI. For each patient that died prior to the cutoff date of March 30, 2009, a mortality date was provided, allowing Kaplan-Meier long-term survival curves to be generated. Cause of death is not available; thus, this study describes all-cause long-term mortality.

\section{Statistical Analysis}

Propensity scoring (PS) analysis was used to mediate selection bias. Propensity analysis involves calculating the probability of being assigned to the treated group and using this probability to make inferences about group effects. In this study, patients were assigned to either OPCAB or standard ONCAB using 41 covariates collected preoperatively, including surgeon identity. Notably, some of these variables have more than 2 levels (such as surgeon, for example) and represent more degrees of freedom in the propensity estimation model than dichotomous or numeric variables. After this PS was calculated for each study patient, it was used as a regression covariate when comparing surgery type. More important, BMI was omitted in calculating the PS because independent inferences were also made for this variable.

To evaluate statistically the effects of surgery type on clinical outcomes in the BMI subgroups, multivariable logistic regression models were constructed. The primary variable under consideration was surgery type (ONCAB or OPCAB). Each model for each outcome was adjusted with the propensity score to account for preoperative differences in the groups. The relationship between OPCAB and ONCAB was examined separately within the BMI strata, and examined for differences across strata (indicative of an interaction). Adjusted odds ratios (AORs), along with $95 \%$ confidence intervals, were computed for each predictor. The reference group for surgery type was $\mathrm{OPCAB}$.

Kaplan-Meier curves were generated that provide unadjusted long-term survival estimates for each BMI group stratified by surgery type. Differences between strata were determined by log-rank tests. Also, 1-, 3-, 5-, $10-$, and 12-year survival was estimated for each combination of BMI 
TABLE 1. Preoperative demographics

\begin{tabular}{|c|c|c|c|c|c|c|}
\hline \multirow[b]{2}{*}{ Characteristic } & \multicolumn{3}{|c|}{$\mathbf{B M I} \leq \mathbf{2 5}$} & \multicolumn{3}{|c|}{ BMI $\geq 35$} \\
\hline & ONCAB $(n=2083)$ & OPCAB $(n=2229)$ & $P$ value & ONCAB $(n=1127)$ & OPCAB $(n=1362)$ & $P$ value \\
\hline Age, mean $\pm S D$ & $65.7 \pm 10.9$ & $66.6 \pm 11.6$ & .006 & $58.2 \pm 10.1$ & $58.9 \pm 10.5$ & .08 \\
\hline Female gender, $\mathrm{n}(\%)$ & $653(31.4)$ & $796(35.7)$ & $<.001$ & $408(36.2)$ & $573(42.1)$ & .003 \\
\hline White, $\mathrm{n}(\%)$ & $1680(83.1)$ & $1712(77.4)$ & $<.001$ & $891(80.9)$ & $1004(74.1)$ & $<.001$ \\
\hline \multicolumn{7}{|l|}{ Status, n (\%) } \\
\hline Elective & $1673(80.3)$ & $1512(67.8)$ & $<.001$ & 897 (79.6) & $929(68.2)$ & $<.001$ \\
\hline Urgent & $236(11.3)$ & $645(28.9)$ & & $154(13.7)$ & $394(28.9)$ & \\
\hline Emergency & $174(8.4)$ & $72(3.2)$ & & $76(6.7)$ & $39(2.9)$ & \\
\hline Ejection fraction, $\%$; mean $\pm \mathrm{SD}$ & $48.4 \pm 13.7$ & $50.3 \pm 13.1$ & $<.001$ & $49.9 \pm 12.5$ & $51.8 \pm 11.9$ & $<.001$ \\
\hline Hypertension, n (\%) & $1405(67.5)$ & $1738(78.0)$ & $<.001$ & $949(84.2)$ & $1216(89.3)$ & $<.001$ \\
\hline Chronic lung disease, $\mathrm{n}(\%)$ & $389(18.7)$ & $489(21.9)$ & .008 & $141(12.5)$ & $241(17.7)$ & $<.001$ \\
\hline Previous myocardial infarction, $\mathrm{n}(\%)$ & $1166(56.0)$ & $1178(52.9)$ & .039 & $620(55.0)$ & $693(50.9)$ & .04 \\
\hline Previous CVA, n (\%) & $182(8.7)$ & $252(11.3)$ & .005 & $76(6.7)$ & $119(8.7)$ & .07 \\
\hline Previous valve surgery, $\mathrm{n}(\%)$ & $7(0.3)$ & $5(0.2)$ & .49 & $2(0.2)$ & $2(0.2)$ & .85 \\
\hline Previous sternotomy, n (\%) & $167(8.0)$ & $65(2.9)$ & $<.001$ & $81(7.2)$ & $32(2.3)$ & $<.001$ \\
\hline $\mathrm{BMI}$, mean $\pm \mathrm{SD}$ & $22.8 \pm 1.9$ & $22.5 \pm 2.0$ & $<.001$ & $39.2 \pm 4.2$ & $39.6 \pm 4.6$ & .012 \\
\hline Cerebrovascular disease, n (\%) & $330(15.8)$ & $470(21.1)$ & $<.001$ & $114(10.1)$ & $192(14.1)$ & .003 \\
\hline Peripheral vascular disease, $\mathrm{n}(\%)$ & $196(9.4)$ & $378(17.0)$ & $<.001$ & $72(6.4)$ & $123(9.0)$ & .015 \\
\hline Serum creatinine, mean $\pm \mathrm{SD}$ & $1.24 \pm 1.07$ & $1.28 \pm 1.30$ & .41 & $1.19 \pm 0.88$ & $1.27 \pm 1.30$ & .08 \\
\hline Chronic renal insufficiency, n (\%) & $155(7.4)$ & $170(7.6)$ & .82 & $77(6.8)$ & $98(7.2)$ & .72 \\
\hline Preoperative dialysis, $\mathrm{n}(\%)$ & 39 (1.9) & $82(3.7)$ & $<.001$ & $11(1.0)$ & $36(2.6)$ & .002 \\
\hline Dyslipidemia, n (\%) & $450(21.6)$ & $1379(61.9)$ & $<.001$ & $334(29.6)$ & $926(68.0)$ & $<.001$ \\
\hline Current smoker, n (\%) & $786(37.7)$ & $1256(56.4)$ & $<.001$ & $393(34.9)$ & $637(46.8)$ & $<.001$ \\
\hline Preoperative IABP, n (\%) & $75(3.6)$ & $57(2.6)$ & .047 & $40(3.6)$ & $35(2.6)$ & .15 \\
\hline Immunosuppressive therapy, $\mathrm{n}(\%)$ & $50(2.4)$ & $101(4.5)$ & $<.001$ & $26(2.3)$ & $44(3.2)$ & .17 \\
\hline $\mathrm{STS}$ PROM, mean $\pm \mathrm{SD}$ & $0.028 \pm 0.035$ & $0.031 \pm 0.043$ & .043 & $0.017 \pm 0.021$ & $0.018 \pm 0.025$ & .049 \\
\hline
\end{tabular}

$B M I$, Body mass index; $O N C A B$, on-pump coronary artery bypass grafting; $O P C A B$, off-pump coronary artery bypass grafting; $S D$, standard deviation; $C V A$, cerebrovascular accident; IABP, intra-aortic balloon pump; STS PROM, Society of Thoracic Surgeons predicted risk of mortality.

and surgery type. A total of 313 patients operated on after the last SSDI harvest dates were excluded from the survival analysis.

Last, kernel estimation with uniform smoothing was used to assess visually the relationship between numeric BMI and mortality rates. A plot was created in which the $x$-axis was BMI and the $y$-axis was observed mortality. Because observed mortality is dichotomous, the points on the plot at each BMI value are calculated by taking an average of the observed mortality (so-called uniform kernel smoothing) for a neighborhood around the BMI value. The neighborhood is defined as the collection of points within a small range around the BMI value; thus, the point on the plot is the average mortality rate for that neighborhood of BMI values. The width of each neighborhood was held fixed at $10 \%$.

The data were managed and analyzed using SAS version 9.2 (SAS Institute, Inc, Cary, NC). Unadjusted comparisons were performed with $\chi^{2}$ tests and 2-sample $t$ tests for categoric and numeric predictors, respectively. All statistical tests were 2-sided using an $\alpha=.05$ level of significance. No multiple comparisons adjustments were deemed necessary.

\section{RESULTS}

\section{Preoperative and Operative Data}

Of the 6801 patients included for analysis, 4312 patients had a BMI $<25$ and 2489 had a BMI $>35$. Preoperative demographics are highlighted in Table 1 . Most notable, patients who underwent $\mathrm{OPCAB}$ in both BMI groups were older, more frequently female, less frequently white, and had a greater incidence of many preoperative comorbidities. Patients undergoing ONCAB had a significantly lower ejection fraction and higher incidence of redo surgery than their OPCAB counterparts, but STS predicted risk of mortality was significantly greater for the OPCAB groups in both BMI strata.

Operative data including $\mathrm{CPB}$ and ischemic times are detailed in Table 2. There was a higher incidence of redo surgery in those patients who underwent ONCAB, and intraoperative intra-aortic balloon counterpulsation was more frequent in ONCAB patients.

\section{Postoperative Outcomes}

Adjusted outcomes using a multivariable propensity analysis of preoperative covariates are detailed in Table 3. Most notable are the outcomes for the group of patients with a BMI $<25$. There was a significantly decreased incidence of death $(\mathrm{AOR}=0.48)$, stroke $(\mathrm{AOR}=0.31)$, major adverse cardiac events $(\mathrm{AOR}=0.41)$, mediastinitis $(\mathrm{AOR}=0.13)$, new-onset renal failure $(\mathrm{AOR}=0.59)$, and prolonged ventilation $(\mathrm{AOR}=0.50)$ associated with the OPCAB group. For patients with a BMI $>35$, only major adverse cardiac events were reduced significantly with OPCAB $(A O R=0.51)$. Figure 1 depicts in-hospital mortality by BMI and surgery type using a smooth kernel estimation. On-pump CABG patients with BMI $<25$ 
TABLE 2. Operative data by body mass index classification and surgery type

\begin{tabular}{|c|c|c|c|c|c|c|}
\hline Operative variable & $\begin{array}{c}\text { BMI } \leq 25 \\
\text { ONCAB }(n=2083)\end{array}$ & $\begin{array}{c}\text { BMI } \leq 25 \\
\text { OPCAB }(n=2229)\end{array}$ & $\begin{array}{c}P \\
\text { value }\end{array}$ & $\begin{array}{c}\text { BMI } \geq 35 \\
\text { ONCAB }(\mathbf{n}=1127)\end{array}$ & $\begin{array}{c}\text { BMI } \geq 35 \\
\text { OPCAB }(n=1362)\end{array}$ & $\begin{array}{c}P \\
\text { value }\end{array}$ \\
\hline Aortic crossclamp time, min; mean $\pm \mathrm{SD}$ & $49.5 \pm 23.7$ & 0 & - & $53.2 \pm 24.2$ & 0 & - \\
\hline $\mathrm{CPB}$ time, min; mean $\pm \mathrm{SD}$ & $92.5 \pm 30.0$ & 0 & - & $96.5 \pm 31.8$ & 0 & - \\
\hline No. of distal Anastomosis, mean \pm SD & $3.45 \pm 0.97$ & $2.91 \pm 1.07$ & $<.001$ & $3.51 \pm 0.94$ & $2.93 \pm 1.08$ & $<.00$ \\
\hline No. of proximal anastomosis, mean \pm SD & $1.58 \pm 1.25$ & $1.40 \pm 1.05$ & $<.001$ & $1.52 \pm 1.27$ & $1.33 \pm 1.04$ & $<.00$ \\
\hline LITA usage, $\mathrm{n}(\%)$ & $1771(85.0)$ & $1897(85.1)$ & .94 & $999(88.6)$ & $1212(89.0)$ & .79 \\
\hline Intraoperative IABP insertion, $\mathrm{n}(\%)$ & $104(5.0)$ & $39(1.8)$ & $<.001$ & $40(3.6)$ & $14(1.0)$ & $<.00$ \\
\hline
\end{tabular}

$B M I$, Body mass index; $O N C A B$, on-pump coronary artery bypass grafting; $O P C A B$, off-pump coronary artery bypass grafting; $S D$, standard deviation; $C P B$, cardiopulmonary bypass; LITA, left internal thoracic artery; IABP, intra-aortic balloon pump.

had significantly poorer mortality than their OPCAB counterparts.

\section{Long-Term Outcomes}

Long-term survival is detailed in Table 4 and Figures 1 and 2. The most notable divide is between underweight and overweight patients. Underweight patients have poorer early survival, and the survival gap continues to widen out to 12 years. Although there was an improvement in shortterm mortality, long-term mortality is not different between surgery type in either underweight or overweight patients. However, there is a statistically improved survival in all patients with a BMI $>35$ compared with those with a BMI $<25(P<.001)$.

\section{DISCUSSION}

Surgical coronary revascularization has long been established as an important and effective component for treatment for certain patients with coronary artery disease. Most recent research involving CABG has sought to evaluate modifiable variables surrounding operative conduct and patient selection to improve short- and long-term outcomes. On-pump CABG represented one such innovation: the possibility of avoiding CPB while providing equivalent revascularization may benefit certain patient populations. Not surprisingly, OPCAB has been shown to benefit those patients at highest preoperative risk. ${ }^{15}$ What has yet to be detailed completely is the risk that low BMI poses to patients in terms of short- and long-term outcomes. Of the 3 commonly used preoperative risk calculators used in cardiac surgery, only the STS risk assessment calculator has inputs available to account for individual body mass indices. $^{18-20}$

This study reinforces results published by prior researchers, specifically that patients with a low BMI incurred greater morbidity and mortality after CABG. ${ }^{16,17}$ The novelty of this study, however, was the comparison between patients at body mass extremes undergoing OPCAB versus ONCAB. The decision to label BMI parameters extreme at $>35$ and $<25$ stemmed from data from our own institution as well as prior research conducted on the subjects of cardiac surgery and BMI. ${ }^{16,17,21}$ On univariate analysis of the 4 groups of patients, the 2 OPCAB groups had notably more preoperative comorbidities than the 2 ONCAB groups, including higher preoperative rates of cerebrovascular disease and chronic lung disease. There were exceptions; both ONCAB groups had statistically lower ejection fractions than their respective OPCAB counterparts. When STS predicted risk of mortality scores were compared, both OPCAB groups had significantly higher predicted risk of mortality scores than ONCAB groups.

TABLE 3. Multivariable adjusted analysis of postoperative outcomes

\begin{tabular}{|c|c|c|c|c|c|c|}
\hline \multirow[b]{2}{*}{ OUTCOME } & \multicolumn{3}{|c|}{ BMI $<25$} & \multicolumn{3}{|c|}{ BMI > 35} \\
\hline & ONCAB $(n=2083)$ & OPCAB $(n=2229)$ & AOR $(95 \%$ CI $)$ & ONCAB $(n=1127)$ & $\operatorname{OPCAB}(n=1362)$ & $\operatorname{AOR}(95 \% \mathrm{CI})$ \\
\hline Death & $78(3.7)$ & $36(1.6)$ & $0.48(0.28-0.82)^{*}$ & $24(2.1)$ & $15(1.1)$ & $0.45(0.19-1.07)$ \\
\hline Stroke & $65(3.1)$ & $28(1.3)$ & $0.31(0.18-0.56)^{*}$ & $16(1.4)$ & $19(1.4)$ & $0.52(0.22-1.23)$ \\
\hline Myocardial infarction & $26(1.3)$ & $16(0.7)$ & $0.62(0.26-1.49)$ & $12(1.1)$ & $5(0.4)$ & $1.18(0.26-5.28)$ \\
\hline $\begin{array}{l}\text { Major adverse cardiac } \\
\text { events }\end{array}$ & $154(7.4)$ & $73(3.3)$ & $0.41(0.28-0.60)^{*}$ & $49(4.4)$ & $36(2.6)$ & $0.51(0.28-0.93)^{*}$ \\
\hline Mediastinitis & $19(0.9)$ & $6(0.3)$ & $0.13(0.05-0.38)^{*}$ & $33(2.9)$ & $27(2.0)$ & $0.59(0.29-1.19)$ \\
\hline Septicemia & $35(1.7)$ & $28(1.3)$ & $1.04(0.50-2.15)$ & $20(1.8)$ & $21(1.5)$ & $0.70(0.30-1.62)$ \\
\hline Renal failure & $72(3.5)$ & $52(2.3)$ & $0.59(0.36-0.96)^{*}$ & $66(5.9)$ & $84(6.2)$ & $0.81(0.52-1.29)$ \\
\hline New dialysis & $18(0.9)$ & $18(0.8)$ & $0.45(0.19-1.05)$ & $15(1.3)$ & $25(1.8)$ & $0.74(0.32-1.72)$ \\
\hline Prolonged ventilation & $230(12.8)$ & $230(10.7)$ & $0.50(0.38-0.64) *$ & $136(13.5)$ & $223(16.7)$ & $0.77(0.57-1.05)$ \\
\hline
\end{tabular}




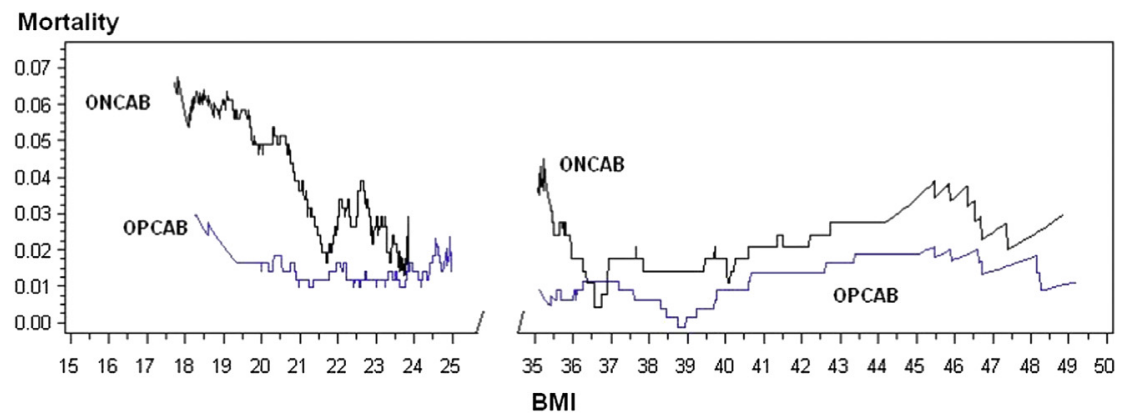

FIGURE 1. Smooth kernel estimation of mortality by body mass index for off-pump coronary artery bypass grafting and on-pump coronary artery bypass grafting. $O P C A B$, Off-pump coronary artery bypass grafting; $B M I$, body mass index; $O N C A B$, on-pump coronary artery bypass grafting.

Operative data for all 4 groups revealed acceptable ischemic and CPB times for the ONCAB groups. Not surprising, both ONCAB groups had a greater number of distal targets grafted. This follows with previously published data from our institution detailing a greater proportion of ONCAB procedures for patients with a greater number of distal targets without sacrificing completeness of revascularization. $^{22,23}$ The incidence of intraoperative intra-aortic balloon pump insertion was higher in both ONCAB groups. This fact may be best explained by the increased incidence of emergency operations performed in the ONCAB populations.

Postoperative adverse events were decreased for both groups undergoing $\mathrm{OPCAB}$, but the differences were more notable for patients at low BMI. Patients with a BMI $<25$ undergoing OPCAB experienced significantly lower rates of postoperative mortality, stroke, and newonset renal failure. Composite outcomes (stroke, death, myocardial infarction) were improved for patients undergoing OPCAB in both BMI groups. Reasons for the improved outcomes observed include the potential for decreased transfusion requirements following $\mathrm{OPCAB}$, a decreased inflammatory response associated with $\mathrm{CPB}$ avoidance, and an increased intraoperative intra-aortic balloon pump counterpulsation requirement for patients who underwent ONCAB. A decreased inflammatory response when compared with $\mathrm{ONCAB}$ has been noted in prior works detailing OPCAB, but this data set does not include serologic data regarding inflammatory markers. ${ }^{24,25}$ Patients with a low BMI may derive benefit preferentially from avoidance of CPB and decreased levels of postoperative circulating levels of proinflammatory cytokines.

Long-term outcomes for patients with a low BMI were unaffected by the type of surgical revascularization. Survival rates at every postoperative time point were lower for patients with a BMI $<25$ when compared with patients with a BMI $>35$. Although no direct comparisons were made between BMI groups, it stood to reason that patients with a lower BMI may be less fit than their obese counterparts at the time of surgery. In addition, the convergence in long-term mortality could be explained potentially by the decrease in completeness of revascularization in OPCAB patients or by a similar progression of disease that rendered revascularization methods equal over prolonged periods. The STS predicted risk of mortality was higher for patients with BMI $<25$ regardless of surgical intervention, and postoperative observed mortality was higher as well.

\section{Limitations}

This was a retrospective observational study and was subject to the usual limitations of this sort of study - most notable, the inability to have full investigative control over the primary study factors. In addition, individual surgeon decision making and technique could not be accounted for in a study of this magnitude. Although practices have been largely standardized, interoperator variability still existed. Also, patients were analyzed according to the treatment they ultimately received. There were 195 conversions

TABLE 4. Long-term outcomes by body mass index and procedure

\begin{tabular}{|c|c|c|c|c|c|c|}
\hline Patient group & 1-y survival, $\%$ & 3-y survival, $\%$ & 5-y survival, \% & $10-y$ survival, $\%$ & 12-y survival, $\%$ & $P$ value \\
\hline $\mathrm{BMI}<25$ OPCAB & 92.9 & 85.0 & 76.2 & 57.8 & 51.3 & .52 \\
\hline $\mathrm{BMI}<25$ ONCAB & 91.2 & 85.1 & 78.1 & 57.4 & 48.9 & \\
\hline $\mathrm{BMI}>35 \mathrm{OPCAB}$ & 95.7 & 90.4 & 85.3 & 64.7 & 43.1 & .16 \\
\hline $\mathrm{BMI}>35 \mathrm{ONCAB}$ & 95.4 & 92.3 & 87.3 & 68.9 & 62.7 & \\
\hline OPCAB & 93.9 & 87.0 & 79.7 & 60.8 & 49.7 & .30 \\
\hline ONCAB & 92.6 & 87.6 & 81.3 & 61.3 & 53.4 & \\
\hline Underweight & 92.0 & 85.2 & 77.5 & 56.8 & 48.6 & $<.001$ \\
\hline Overweight & 95.6 & 91.4 & 86.4 & 67.7 & 61.1 & \\
\hline
\end{tabular}

$B M I$, Body mass index; $O P C A B$, off-pump coronary artery bypass grafting; $O N C A B$, on-pump coronary artery bypass grafting. 


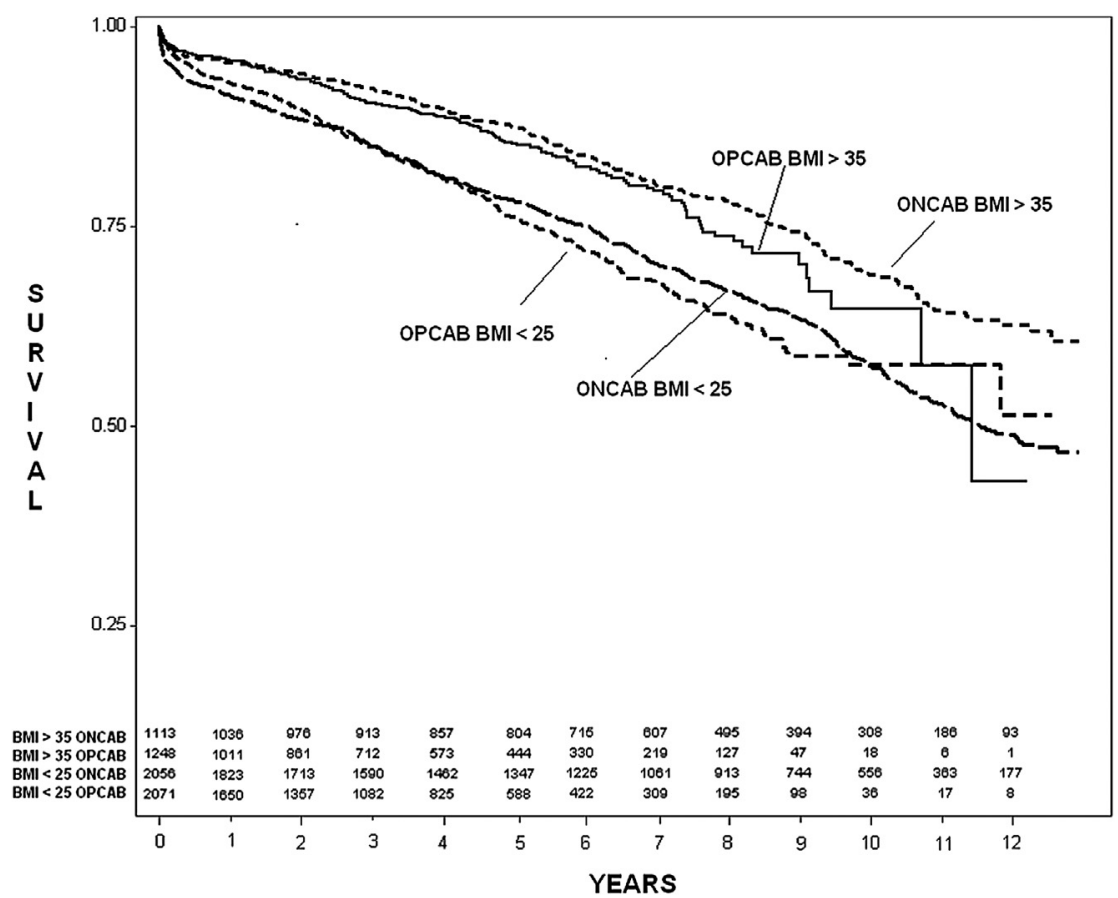

FIGURE 2. Kaplan-Meier survival curve by body mass index $(P<.05)$. ONCAB, On-pump coronary artery bypass grafting; $O P C A B$, off-pump coronary artery bypass grafting; $B M I$, body mass index.

from $\mathrm{OPCAB}$ to ONCAB from 2002 forward, but no conversion information was collected prior to 2002. When the post-2002 conversions were examined under an intentto-treat framework, the primary study results (Table 3 ) did not change significantly. Although it can be assumed in a study of this size that cardiac and noncardiac mortality alike occurred in equal proportions across study subpopulations, long-term mortality was all cause and may not reflect cardiac mortality accurately.

\section{CONCLUSIONS}

Patients with BMIs $<25$ compared with $>35$ remain a high-risk group undergoing CABG. Short-term outcomes are improved in those patients with a BMI $<25$ who underwent coronary artery bypass without the use of the CPB circuitry. Long-term outcomes are similar among surgical groups. Further methods should be researched to attenuate morbidity and mortality for patients at either BMI extremes.

The authors from Emory University express their gratitude to staff members Kim Baio for project oversight, to Jean Walker and Susan Joyce for data abstraction, and to Deborah Canup for database management.

\section{References}

1. Caracciolo EA, Davis KB, Sopko G, Kaiser GC, Corley SD, Schaff H, et al. Comparison of surgical and medical group survival in patients with left main coronary artery disease: long-term CASS experience. Circulation. 1995;91:2325-34.

2. Shapira I, Isakov A, Yakirevich V, Topilsky M. Long-term results of coronary artery bypass surgery in patients with severely depressed left ventricular function. Chest. 1995;108:1546-50.
3. Hammar N, Sandberg E, Larsen FF, Ivert T. Comparison of early and late mortality in men and women after isolated coronary artery bypass graft surgery in Stockholm, Sweden, 1980 to 1989. J Am Coll Cardiol. 1997;29:659-64.

4. Myers WO, Blackstone EH, Davis K, Foster ED, Kaiser GC. CASS Registry long term surgical survival: Coronary Artery Surgery Study. J Am Coll Cardiol. 1999; 33:488-98.

5. Zacharias A, Schwann TA, Riordan CJ, Durham SJ, Shah AS, Habib RH. Late results of conventional versus all-arterial revascularization based on internal thoracic and radial artery grafting. Ann Thorac Surg. 2009;87:19-26.

6. Hueb W, Lopes NH, Pereira AC, Hueb AC, Soares PR, Favarato D, et al. Fiveyear follow-up of a randomized comparison between off-pump and on-pump stable multivessel coronary artery bypass grafting: the MASS III trial. Circulation. 2010;122:S48-52.

7. Puskas JD, Kilgo PD, Lattouf OM, Thourani VH, Cooper WA, Vassiliades TA, et al. Off-pump coronary bypass provides reduced mortality and morbidity and equivalent 10-year survival. Ann Thorac Surg. 2008;86:1139-46; Discussion, 1146.

8. Park DW, Kim YH, Yun SC, Lee JY, Kim WJ, Kang SJ, et al. Long-term outcomes after stenting versus coronary artery bypass grafting for unprotected left main coronary artery disease: 10-year results of bare-metal stents and 5-year results of drug-eluting stents from the ASAN-MAIN (ASAN Medical Center-Left MAIN Revascularization) registry. J Am Coll Cardiol. 2010;56: 1366-75.

9. Park DW, Seung KB, Kim YH, Lee JY, Kim WJ, Kang SJ, et al. Long-term safety and efficacy of stenting versus coronary artery bypass grafting for unprotected left main coronary artery disease: 5-year results from the MAIN-COMPARE (Revascularization for Unprotected Left Main Coronary Artery Stenosis: Comparison of Percutaneous Coronary Angioplasty Versus Surgical Revascularization) registry. J Am Coll Cardiol. 2010;56:117-24.

10. Hannan EL, Racz MJ, Walford G, Jones RH, Ryan TJ, Bennett E, et al. Longterm outcomes of coronary-artery bypass grafting versus stent implantation. $N$ Engl J Med. 2005;352:2174-83.

11. Shroyer AL, Grover FL, Hattler B, Collins JF, McDonald GO, Kozora E, et al. On-pump versus off-pump coronary-artery bypass surgery. $N$ Engl $\mathrm{J} \mathrm{Med}$. 2009;361:1827-37.

12. Kapur A, Hall RJ, Malik IS, Qureshi AC, Butts J, de Belder M, et al. Randomized comparison of percutaneous coronary intervention with coronary artery bypass grafting in diabetic patients: 1-year results of the CARDia (Coronary Artery Revascularization in Diabetes) trial. J Am Coll Cardiol. 2010;55:432-40. 
13. Mack MJ, Pfister A, Bachand D, Emery R, Magee MJ, Connolly M, et al. Comparison of coronary bypass surgery with and without cardiopulmonary bypass in patients with multivessel disease. J Thorac Cardiovasc Surg. 2004;127:167-73.

14. Magee MJ, Alexander JH, Hafley G, Ferguson TB Jr, Gibson CM, Harrington RA, et al. Coronary artery bypass graft failure after on-pump and off-pump coronary artery bypass: findings from PREVENT IV. Ann Thorac Surg. 2008;85:494-9; Discussion, 499-500.

15. Puskas JD, Thourani VH, Kilgo P, Cooper W, Vassiliades T, Vega JD, et al. Offpump coronary artery bypass disproportionately benefits high-risk patients. Ann Thorac Surg. 2009;88:1142-7.

16. Engelman DT, Adams DH, Byrne JG, Aranki SF, Collins JJ Jr, Couper GS, et al. Impact of body mass index and albumin on morbidity and mortality after cardiac surgery. J Thorac Cardiovasc Surg. 1999;118:866-73.

17. Potapov EV, Loebe M, Anker S, Stein J, Bondy S, Nasseri BA, et al. Impact of body mass index on outcome in patients after coronary artery bypass grafting with and without valve surgery. Eur Heart J. 2003;24:1933-41.

18. The Society of Thoracic Surgeons. Online STS risk calculator. Available at: http://209.220.160.181/STSWebRiskCalc261/de.aspx. Accessed March 30, 2012.

19. Société Française d'Anesthésie et de Réamination. Scoring system for ICU and surgical patients: initial PARSONNET (predictive score for acquired adult heart surgery: additive and logistic regression models). Available at: http://www.sfar. org/scores2/parsonnet2.html. Accessed March 30, 2012.
20. European System for Cardiac Operative Risk Evaluation. EuroSCORE interactive calculator. Available at: http://www.euroscore.org/calc.html. Accessed March 30, 2012.

21. Thourani VH, Keeling WB, Kilgo PD, Puskas JD, Lattouf OM, Dara AB, et al. The impact of body mass index on morbidity and short- and long-term mortality in cardiac valvular surgery. J Thorac Cardiovasc Surg. 2011;142:1052-61.

22. Lattouf OM, Puskas JD, Thourani VH, Noora J, Kilgo PD, Guyton RA. Does the number of grafts influence surgeon choice and patient benefit of off-pump over conventional on-pump coronary artery revascularization in multivessel coronary artery disease? Ann Thorac Surg. 2007;84:1485-94; Discussion, 1494-5.

23. Lattouf OM, Thourani VH, Kilgo PD, Halkos ME, Baio KT, Myung R, et al. Influence of on-pump versus off-pump techniques and completeness of revascularization on long-term survival after coronary artery bypass. Ann Thorac Surg. 2008;86:797-805.

24. Nesher N, Frolkis I, Vardi M, Sheinberg N, Bakir I, Caselman F, et al. Higher levels of serum cytokines and myocardial tissue markers during on-pump versus off-pump coronary artery bypass surgery. J Card Surg. 2006;21:395-402.

25. Dybdahl B, Wahba A, Haaverstad R, Kirkeby-Garstad I, Kierulf P, Espevik T, et al. On-pump versus off-pump coronary artery bypass grafting: more heatshock protein 70 is released after on-pump surgery. Eur J Cardiothorac Surg. 2004;25:985-92. 